\title{
Construction of Innovative Teaching System and Mode for Mechanical Principle Course Facing Ability Target of International Engineering Education
}

\author{
YANG Yong a, ${ }^{a}$, JIANG Jing-liang, WANG De-xiang, JIN Xia \\ School of Mechanical Engineering, Qingdao Technological University, \\ Qingdao 266520, Shandong, China \\ ayyong901@163.com
}

Keywords: Engineering education, Ability, Mechanical principle course, Teaching system.

\begin{abstract}
Aiming at the exist teaching problems of mechanical principle course, facing ability target of international engineering education, a further exploration and practice of teaching reform for mechanical principle course are carried out. The effective constructions are obtained in the following aspects: the course innovation teaching system, new teaching methods, new teaching mode, course practice, teaching evaluation mechanism and system. Practical application shows that the Teaching reform of mechanical principle course is a success, and can fully promote the enthusiasm and initiatives of student's learning as well as develop the students' ability of practice innovative, which meets the rules and standards of engineering education for mechanical principle course.
\end{abstract}

\section{Introduction}

In June 2016, China formally joined the Washington Agreement, indicating that the quality of China's engineering education has been recognized by the international community. At the same time, the agreement also put forward new requirements for engineering education in our country, and that is to cultivate students ability as the primary goal ${ }^{[1-2]}$. The course of mechanical principle, as a main technical basic course of mechanical specialty in Colleges and universities, plays an important role in strengthening and developing the creative ability of students in the overall situation of cultivating advanced mechanical engineering talents. Therefore, the course of mechanical principle, as an important teaching link in mechanical specialty setting in colleges and universities, carries on the important task of realizing the advanced education teaching idea and goal in the new period, and plays an irreplaceable role in cultivating and improving students' ability.

In view of the important role and status of the course of mechanical principle, the teaching of this course has been paid attention to by many universities at home and abroad ${ }^{[3-5]}$. A great deal of reform research has been done on the course of mechanical principle, and some progress has been made. However, limited to the traditional education idea, the teaching reform of the course has not made breakthrough progress. Such as, it is very common to take the teacher as the teaching center, focus on the integrity of theoretical system and only imparting knowledge in classroom teaching. The relationship between curriculum reform and students' ability structure, the methods that embed the curriculum reform into the whole curriculum system and the issue that how to effectively promote the development of students' ability have not given the necessary attention. In this paper, based on the advanced idea of international engineering education and the core of strengthening the engineering practice ability, engineering design ability and engineering innovation ability, we explore and practice the innovative teaching system and teaching mode of mechanical principle course which is compatible with the current national engineering education reform goal. Then, constructing the innovative teaching system and teaching mode under the goal of engineering education ability, and hope to play a reference and demonstration role for the main course reform of the same profession in other colleges and universities. 


\section{Construction of Innovative Teaching System based on Ability Index Points}

Based on the advanced idea of international engineering education, this paper studies the function and task of the mechanical principle course in achieving the goal of engineering education ability. Constituting the teaching system of engineering ability training, including classroom teaching, experiment teaching, curriculum design and other links. By analyzing the relationship between professional training objectives, graduation ability requirements and targets of mechanical principle courses, we cultivate the ability of the target requirements in the classroom teaching, experimental teaching, curriculum design and other teaching links of mechanical principles. Then combining with the course content system, teaching objectives, course characteristics and the position in the specialized course system, we study and form the ability index points of the teaching system of mechanical principle course. Next establishing the index point system of professional ability for the unit knowledge in the classroom teaching link, the index point system for the practical ability, the explore design ability and the comprehensive design ability in the experimental teaching link and the index point system for the innovative design ability, the ability of solving practical problems and the team cooperation ability in the course design link. On this basis, we put forward to the construction method of innovative teaching system in mechanical principle courses based on ability index points, establishing a new teaching system including the classroom teaching, the experimental teaching and the curriculum design based on engineering ability training, and form the distinct innovative teaching system of mechanical principle course which can highlight the cultivation of students' engineering ability.

\section{Study and practice of new teaching method based on CDIO pattern}

As a practice pattern of current international higher engineering education, CDIO has brought significant changes to and impacts on engineering education, which has the remarkable effect on cultivating the abilities of integrative design, innovative practice and team collaboration. But so far, the CDIO pattern has not a wide range of application in China, because of the implementation link which is difficult to come true. To solve this problem, a new application pattern of LAB-CDIO engineering education is put forward to, which integrates the core cultivation concept of CDIO and the features of modern laboratory, such as the openness, compatibility, diversity, reusability and renew ability. The LAB-CDIO pattern performs CDIO process, especially the "Implement and Operate" link, using the laboratory resources. Further, the connotation and advantages, application system, implementation process and laboratory opening mechanism driven by LAB-CDIO pattern of LAB-CDIO are studied. Finally the LAB-CDIO new pattern is applied to the three-level curriculum project of mechanical principle. Practical application shows that the LAB-CDIO engineering education pattern overcomes the defects brought by conventional CDIO pattern, such as high cost, long time, large human input and slow response to the change plan, and can effectively develop the students' ability of engineering practice and engineering innovation. Also, the LAB-CDIO new pattern revitalizes the idle resources of laboratory, and fully displays the effect and potential of experimental equipments, which is a kind of high maneuverable implementation pattern and more suitable for common higher educational institutions.

Different gear train is thought to be a difficulty in mechanical principle course, thus "different mechanism" three-level project is designed to solve this difficulty. A new pattern of CDIO proposed in the paper is applied to this three-level project and specific process of application is as follows:

3.1 Design of "differential" three-level course project.Various typical mechanisms and components are used to design the system of differential in automobile rear bridge and electric motor is served as prime motor. One link's motion is decomposed into two links' in changeable ratio, so in terms of different driving states two rear-wheels of automobile will adjust rotate speed automatically to decrease the slide between tire and ground.

3.2 Conceive, design and proposing solutions. There are many kinds of solutions, according to students' designs, an example is given as follows. 
When motion of electric motor 1 is transmitted to spur gear set 4 through v-belt 2 , its speed is slow then the motion is transmitted to rear axle differential 6 through universal coupling 5. Meanwhile, differential gear train is equipped with angular displacement sensors 7 and 9 in both sides and driving spur gear is equipped with angular displacement sensor 3, so their movement rules can be analyzed by tests. With the help of this transmission scheme, students can master working principle and movement rule of rear axle differential.

3.3 Arrangement of laboratory equipment and components. Laboratory table which is used to innovative design, assembly and simulation of gear train comes to use. This equipment is used to design, analyze and apply and students' abilities which are relevant to innovative design, comprehensive design and practice can be cultivated and raised by assembly and simulation of gear train. Electric motor, v-belt, gear, key, coupling, screwed fittings and stand and so on are used to build the table and component.

3.4 Assembly and building of laboratory equipment and components. According to transmission scheme, students participate in assembly and building of differential system personally by using equipment and components mentioned above.

3.5 Operation of differential system and correction and improvement of scheme. Differential system is operated in laboratory table and its various parameters are regulated. Transmission scheme is amended repeatedly until it is prefect. By testing and analyzing the movement of system students master the function of differential, furtherly they have a deeper comprehension to different gear train and have a acquaintance with engineering application of it.

3.6 Project's defense, exchange and assessing ability. Students will be divided into groups after completing the operation of project. Each group make PPT to defense, exchange the process and experience of scheme's design and submit report of design and then each project will be marked.

\section{Practice of the New Teaching Mode of "Mechanical Principle"}

The implementation of improved CDIO new teaching methods, the need for classroom teaching and practical operation of the combination of this study will be classroom, laboratory, engineering training center, factory practice base and other places to break the teaching space constraints, set up for the mechanical principle Curriculum innovation process teaching system and new teaching methods of the integration of teaching carrier, to explore and practice a cross-space, fusion new teaching mode. The use of the carrier, "mechanical principle" classroom teaching sessions in addition to the classroom, but also in the laboratory and engineering training center, make full use of laboratories and engineering training center hardware resources, the teaching of knowledge and experimental instrument operation, Which can realize the training of the knowledge and ability. The course design can be carried out in the engineering training center and the factory practice base. Through the combination and solving with the practical engineering problems, the engineering innovation and design ability can be cultivated.

\section{A New Teaching Evaluation Mechanism and System}

Teaching evaluation is an indispensable link in guaranteeing the quality of teaching. A new teaching evaluation mechanism of "Mechanics Principle" course is studied, and a "mechanism principle" is formed, which is based on the principle of "the principle of mechanics". The teaching evaluation system based on the ability, the selection of evaluation means - to evaluate - based on the evaluation results to improve the teaching system of scientific evaluation procedures is established, final formation of outstanding ability to assess "mechanical principle" course.

\section{Reform effect}

After a series of reform and practice, the course of "Mechanics Principle" has developed better in the innovative teaching system, the new teaching method, the new teaching mode, the course practice 
link, the teaching evaluation mechanism and the system based on the ability index point. Especially the application of CDIO new teaching method based on laboratory resources, the students have generally reflected that CDIO project training can improve the practical ability and innovative design ability, and broaden the field of vision and generate interest in learning. In the past two years, the mechanical and electrical products at all levels of innovative design competition, won the Seventh National College Students Mechanical Design Competition first prize 2, Shandong Province, mechanical and electrical products, innovative design competition first prize 7 , second prize 9 , The third prize of 6 good results for the best results over the years, which also shows that the above "mechanical theory" curriculum innovation capacity-building system of exploration and construction is more successful.

\section{Acknowledgement}

This work was financially supported by the Key projects of construction engineering education reform of higher education schools in Shandong Province (MX4 - 003).

\section{References}

[1] J. Wu, Ministry of Education to Start and Implement the Program of "A Plan for Educating and Training Outstanding Engineers”, Teaching and Research Trends, vol.7, pp. 8, 2010.

[2] J. Lin, On the Professional Training Program of "A Plan for Educating and Training Outstanding Engineers", Engineering Education Research of Tsinghua University, vol.2, pp. 4, 2011.

[3] H. Z. Wang, J. B. Li, and Y. N. Fei, Layout and Practice of New Course Project Based on the CDIO Syllabus in the Teaching of Machines and Mechanisms Theory, Higher Education Forum, vol.4, pp. 25-27, 2009.

[4] X. C. Li and Z. Y. Qin, Study on Reform for Curriculum Design of the Theory of Mechanisms, Journal of Taiyuan University of Technology (SOCIAL SCIENCE EDITION), vol.26, pp. 48-50, 2008.

[5] H. Q. Zhao, B. L. Guo, and D. F. Zhao, Inspirations of Overseas Cooperative Education of Production and Learning for China's Implementation of the Plan of Cultivation Excellent Engineers, Higher Education of Sciences, vol.4, pp. 49-52, 2010. 